of labour and normal delivery occurred at 38 weeks. The birthweight of the first twin was $2720 \mathrm{~g}$, and the Apgar score 9 at one minute. The second twin was severely macerated and autolysed. There was a single placenta. The cord to the first twin contained three vessels and was centrally inserted. The cord to the macerated twin was inserted marginally.

Intestinal obstruction on the first day of life in the surviving twin led to the discovery of ileal atresia which was treated surgically. Poor feeding, irritability, and grossly delayed development led to admission to hospital at 4 months of age. The occipitofrontal head circumference was $43.8 \mathrm{~cm}$, on the 97 th centile. The fundi were normal. Skull transillumination showed left hydranencephaly. Computed tomography showed that the left cerebral hemisphere had been replaced by fluid, with disorganised and abnormal development of the ventricular system on the right. The lymphocyte karyotype was normal and metabolic screening and a search for evidence of intrauterine infection were negative. At the age of 5 years he is severely handicapped and functioning at the level of a 6 week old child.

\section{Discussion}

The unusual feature of this child is the ability to be almost certain about the pathogenesis of his unique combination of hydranencephaly and ileal atresia. It is likely that death of a monozygotic co-twin caused release of thrombotic debris into the circulation of the surviving twin, leading to both the cerebral and intestinal defects.

Even excluding conjoined twins, there is an excess of congenital malformations in monozygotic twins compared with dizygotic twins or singletons. ${ }^{5}$ Either the monozygotic twinning and the malformation share a common aetiology, or the malformation is a consequence of the twinning process. Death of a twin causing embolisation and vascular disruption of a co-twin is thought to cause hydranencephaly, porencephaly, microcephaly, intestinal atresia, congenital skin defects, and limb amputation. ${ }^{5}$ Vascular disruption due to various reasons is increasingly being recognised as a cause of congenital malformations. ${ }^{6}$ If a macerated or autolysed twin is found at birth, the paediatrician should be alerted to the possibility of serious and not immediately obvious defects in the surviving co-twin.

This child was shown at a clinical meeting of the Section of Paediatrics, Royal Society of Medicine on 28 November 1980. I thank Dr D Donnai and Dr R W Newton for their help, and Miss Michelle Turner for typing the manuscript.

\section{References}

1 Yoshioka H, Kadomoto Y, Mino M, Morikawa Y, Kasubuchi Y, Kusunoki T. Multicystic encephalomalacia in liveborn twin with a still born macerated co-twin. J Pediatr 1979;95; 798-800.

2 Melnick M. Brain damage in survivor after in-utero death of monozygous co-twin. Lancet 1977;ii: 1287 .

3 Jung JH, Graham JM, Schultz N, Smith DW. Congenital hydranencephaly/porencephaly due to vascular disruption in monozygotic twins. Pediatrics 1984;73:467-9.

${ }^{4}$ Louw JH, Cywes S, Davies MRQ, Rode H. Congenital jejunoileal atresia: observations on its pathogenesis and treatment. $Z$ Kinderchir 1981;33:3-17.

5 Schinzel AAGL, Smith DW, Miller JR. Monozygotic twinning and structural defects. J Pediatr 1979;95:921-30.

6 Van Allen MI. Fetal vascular disruptions: mechanisms and some resulting birth defects. Pediatr Ann 1981;10:219-33.

Correspondence to Dr T J David, Booth Hall Children's Hospital, Manchester M9 2AA.

Received 20 August 1984

\title{
Treatment of severe coagulation disturbances as a condition of improved prognosis in fulminant liver failure
}

SUMMARY A favourable outcome of fulminant liver failure by replacement treatment with antithrombin III, prothrombin concentrate, fresh frozen plasma, and plasminogen is reported. Haemostatic balance was maintained and no severe bleeding complications occurred during the 15 days of disturbed liver function.
The mortality rate for patients with coma after hepatic necrosis is still between 65 and $90 \% .^{12}$ There is some evidence that the coagulation disturbances observed in the course of fulminant hepatic failure may act as an intermediary in the pathogenesis of the hepatic necrosis and that rapid correction of haemorrhagic diathesis may lead to an improved prognosis. ${ }^{34}$ We report our treatment of a child with acute hepatic coma of unknown origin. 


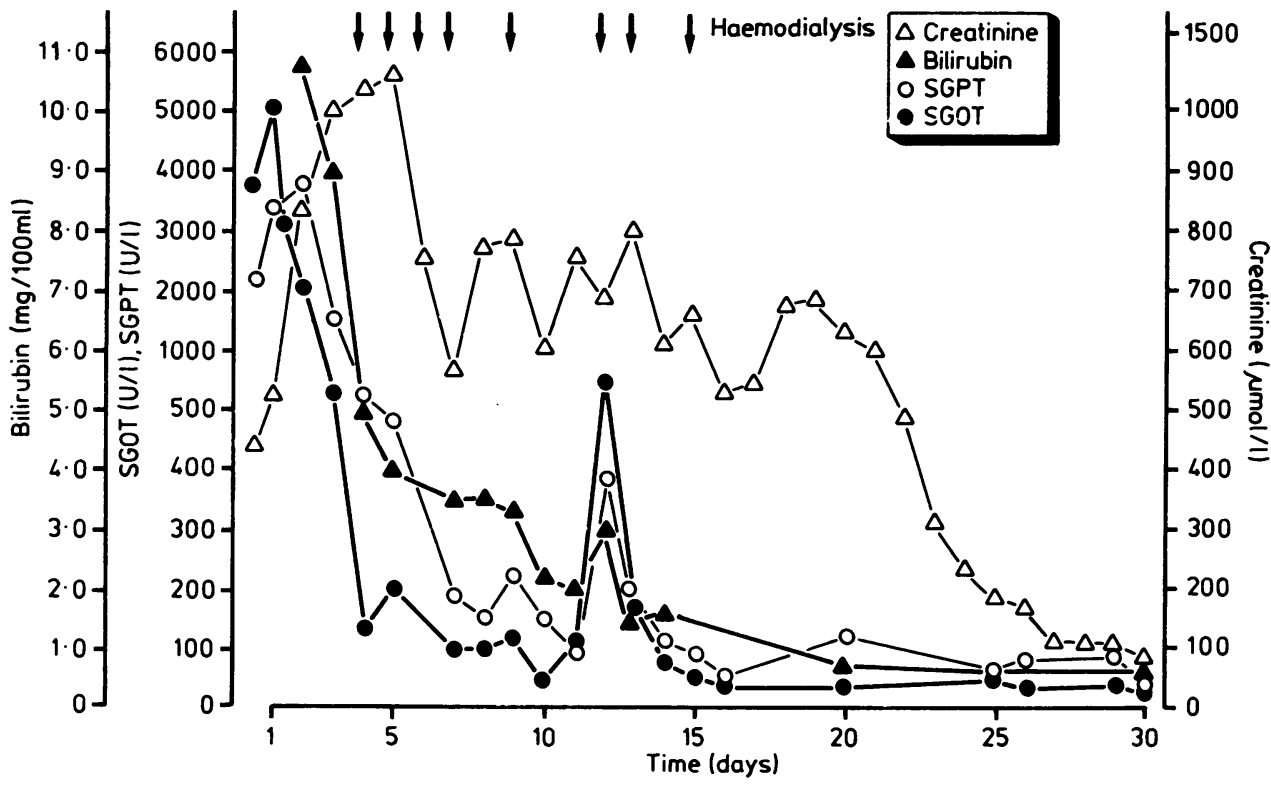

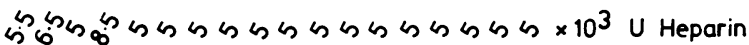

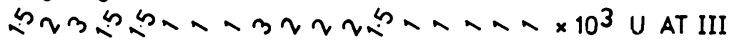

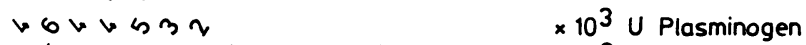

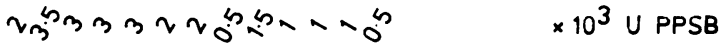

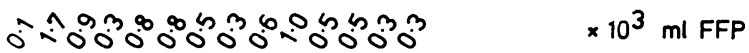

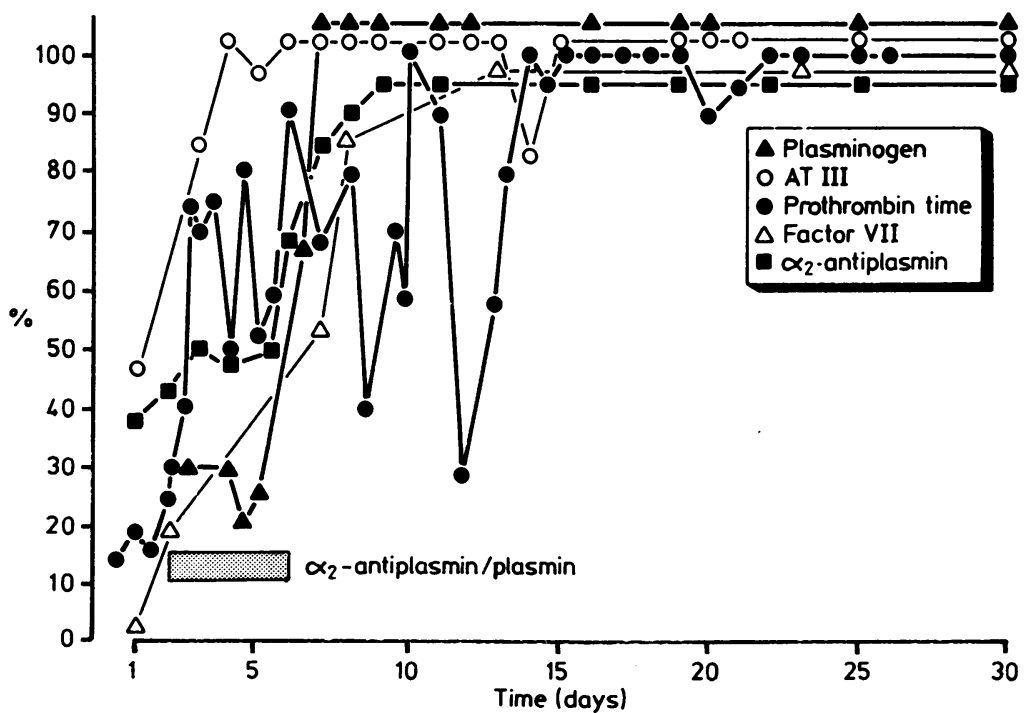

Figure Clinical course, replacement treatment, and coagulation data in a patient with fulminant liver failure. AT III =antithrombin III: PPSB=prothrombin concentrate; FFP=fresh frozen plasma. 


\section{Case report}

A 14 year old boy was admitted to hospital after a 24 hour illness characterised by spontaneous vomiting and drowsiness. There was no history for drug abuse or toxins. Physical examination showed a moderately ill boy with deep jaundice. The liver was palpable $4 \mathrm{~cm}$ below the right costal margin, no foetor hepaticus was noted. His mental state alternated between stupor, disorientation, and wild excitation. Laboratory studies yielded the following results: total bilirubin $131.6 \mu \mathrm{mol} / 1(7.7 \mathrm{mg} / 100 \mathrm{ml})$; direct bilirubin $95.7 \mu \mathrm{mol} / \mathrm{l}(5.6 \mathrm{mg} / 100 \mathrm{ml})$; serum glutamic oxaloacetic transaminase $3872 \mathrm{U} / \mathrm{l}$; serum glutamic pyruvic transaminase $2160 \mathrm{U} / \mathrm{l} ; \gamma$ glutamyltransferase $35 \mathrm{U} / \mathrm{l}$, alkaline phosphatase $872 \mathrm{U} / \mathrm{l}$; total serum protein $49 \mathrm{~g} / 1$; cholinesterase 4.7 $\mathrm{KAU} / 1$; and ammonia $259 \mu \mathrm{mol} / \mathrm{l}$.

The results of initial coagulation studies were: prothrombin time $14 \%$, partial thromboplastin time 66 seconds, thrombin time 29 seconds, fibrinogen $320 \mathrm{mg} / 100 \mathrm{ml}$; factor II $88 \%$, factor V $54 \%$, factor VII $1 \%$, factor VIII $100 \%$, factor IX $20 \%$, antithrombin III $47 \%$, plasminogen $30 \%$, $\alpha 2$-antiplasmin $43 \%, \alpha 2$-antiplasmin-plasmin-complex positive, fibrinogen split products substantively increased to greater than $100 \mu \mathrm{g} / \mathrm{ml}$; platelet count decreased to a minimum of $88 \times 10^{9} / 1$ on the second day after admission to hospital.

Urinary output was reduced to $53 \mathrm{ml} / 24$ hours and his serum creatinine concentration was initially raised at $450 \mu \mathrm{mol} / \mathrm{l}(5 \cdot 1 \mathrm{mg} / 100 \mathrm{ml})$ with a subsequent rise to a maximum of $1260 \mu \mathrm{mol} / \mathrm{l}(14 \cdot 3$ $\mathrm{mg} / 100 \mathrm{ml}$ ).

Antibody studies, including hepatitis-, cytomegalo-, herpes-, coxsackie-, adeno-, reo-, and Epstein-Barr virus infections were entirely negative on repeated determination.

The clinical course and selected laboratory data are summarised in the Figure. Within 12 hours of hospital admission, the patient became comatose and required mechanical ventilation. Replacement of antithrombin III, plasminogen, and procoagulants was begun immediately after diagnosis and heparin was given simultaneously. In spite of the initial fluctuation in prothrombin time, haemostatic balance was maintained during the subsequent 15 days of disturbed liver function and no severe bleeding complications occurred.

Due to rapid deterioration of renal function, haemodialysis was necessary between days 4 and 15 . As liver function recovered diuresis increased gradually. The patient was awake and responsive for the first time on day 19 and was discharged home three months after admission without any obvious hepatic, renal, or neurological disturbances.
Percutaneous liver biopsy performed after hepatic function and coagulation disturbances resolved showed focally accentuated portal round cell infiltration without fibrosis. No fatty degeneration, but moderate regenerative activity of liver cells was noted. Hepatitis B antigen was absent in immunopathological examination.

\section{Discussion}

Efforts to reduce the high mortality from fulminant liver failure have included procedures such as peritoneal dialysis, haemodialysis, plasmapheresis haemoperfusion, exchange transfusion, heterologous liver perfusion, and cross circulation. In paediatric patients there is wide experience only with exchange transfusion. The data on survival rates are conflicting, ${ }^{15}$ however, in a controlled study in adults, exchange transfusion was found to be of no benefit. ${ }^{6}$

Various reports emphasise the importance of supportive treatment in hepatic failure, and there is some evidence in adults that the prevention of bleeding complications, in particular, may improve the prognosis. ${ }^{2-4}$

In fulminant liver failure, a rapidly decreasing activity of coagulation factors and inhibitors, particularly of antithrombin III, has been suggested by two mechanisms: increased consumption in intravascular coagulation, stimulated by the necrosis of hepatocytes and impaired hepatic synthesis. ${ }^{3}$ The developing thrombotic haemorrhagic syndrome results in an ischaemic damage of liver tissue after thrombotic occlusion of the hepatic microcirculation.

Similar mechanisms-increased turnover and impaired hepatic synthesis-have been suggested concerning the lack of factors and inhibitors of the fibrinolytic system. ${ }^{3}$ In agreement with this pathophysiological concept, our coagulation studies showed simultaneously features of intravascular coagulation, hyperfibrinolysis, and impaired production of factors and inhibitors of coagulation and fibrinolysis.

Encouraging results in the treatment of acute liver failure have been reported since 1979 by Egbring and Vogel. ${ }^{3}{ }^{4}$ Similar to our treatment, the regimen of these authors consisted of a rapid elevation of inhibitor values by replacement of antithrombin III-concentrate and subsequent low dose heparin treatment. Replacement of the coagulation factors II, VII, IX, and X was achieved by prothrombin concentrate, factor $\mathrm{V}$, and other inhibitors like $\alpha 2$ antiplasmin were replaced by fresh frozen plasma. Impaired production and increased consumption of fibrinolytic activity were corrected by plasminogen concentrate. Five adult patients with fulminant 
hepatic necrosis treated consecutively according to this regimen at the Centre of Internal Medicine, University of Marburg, survived, and complete functional recovery was achieved.

It is concluded that the effective control of coagulation disturbances in fulminant hepatic failure may improve the prognosis. The rapid and sustained replacement treatment may prevent secondary damage of hepatic function as a result of thrombotic occlusion of the microcirculation affecting the regenerative capacity of hepatocytes. The nearly normal liver biopsy in our patient seems to confirm the efficacy of the treatment.

It must be stressed that only patients treated early in the course of the disease may benefit from replacement treatment; at a certain stage damage of the liver and of other organs as well as the associated coagulation disturbances may become irreversible.

\section{References}

I Marks MI, Mauer SM, Goldman H. Exchange transfusion in the treatment of hepatic coma. J Pediatr 1969;75:418-30.

2 Rake MO, Flute PT, Shilkin KB, Lewis ML, Winch J, Williams R. Early and intensive therapy of intravascular coagulation in acute liver failure. Lancet 1971;ii:1215-8.

${ }^{3}$ Egbring R, Klingemann HG, Heimburger N, et al. Antithrombin III substitution in acute hepatic failure duc to $\mathrm{CCl}_{4}$ intoxication. Thromb Haemost 1981:46:373

+ Vogel G, Bottermann P, Kuhlencordt M. et al. Antithrombin III (AT III) in der Bchandlung von Gerinnungsstörungen beim akuten Leberversagen. Verh Dtsch Ges Inn Med 1979;85: 477-80.

5 Zacarias JS, Brinck P. Huidobro JG. Exchange transfusion in the treatment of hepatic coma. J Pediatr 1967;71:660-4.

' Redecker AG, Yamahiro HS. Controlled trial of exchangetransfusion therapy in fulminant hepatitis. Lancet 1973;i:3-6.

Correspondence to Dr R Burghard, Philipps-University of Marburg. Deutschhausstrasse 12, 3550 Marburg, Germany.

Received 13 September 1984

\title{
Ultrasound monitoring of diaphragm activity in bilateral diaphragmatic paralysis
}

\author{
R AMBLER, S GRUENEWALD, AND E JOHN \\ Departments of Paediatrics, Nuclear Medicine, and Ultrasound, Westmead Centre, Australia
}

SUMMARY Recovery of diaphragm activity after bilateral diaphragmatic paralysis was monitored in a term infant using a mechanical sector scanner fitted with a $5 \mathrm{MHz}$ transducer. The ratio of diaphragmatic excursion during spontaneous breathing and ventilator assistance was used as an objective measure for comparison of diaphragmatic activity during recovery. Ultrasound assessment of diaphragm contraction may be used to study progress in diaphragmatic paralysis.

Bilateral diaphragmatic paralysis secondary to birth trauma is a rare occurrence ${ }^{1}$ and most of these babies require ventilatory assistance soon after birth. ${ }^{2}$ Assessment of diaphragmatic recovery clinically or by fluoroscopy becomes difficult once ventilatory assistance has begun. We describe an infant with bilateral diaphragmatic paralysis whose recovery was monitored ultrasonically.

\section{Case report}

A boy weighing $2650 \mathrm{~g}$ was born at term to a 25 year old mother after an uneventful pregnancy and the spontaneous onset of labour. Fetal bradycardia was noted during the second stage of labour and delivery was expedited using Keilland's forceps. Apgar scores were 3 and 4 at one and five minutes respectively. He was intubated at one minute and ventilated with $100 \%$ oxygen. Soon after ventilation began his $\mathrm{pH}$ was 7.04 with a base deficit of 19 $\mathrm{mmol} / \mathrm{l}$. On examination, the infant was hypotonic with no spontaneous movements below the neck. Spontaneous movement of the legs was seen on day 2 and this gradually extended cranially, partial recovery of the deltoid having occurred by day 7 . Inadequate, jerky, inspiratory efforts were first seen on day 12. Diaphragmatic activity was studied on several occasions using real time ultrasound.

Ultrasound images of the right hemidiaphragm were obtained using a mechanical sector scanner fitted with a $5 \mathrm{MHz}$ transducer (Honeywell Ultraimager). The transducer was placed below the right costal margin, and with the liver providing an acoustic window, saggital views were obtained of the posterior portion of the diaphragm until maximum diaphragmatic excursion was observed (Fig. 1). The transducer was held in this position and the movement of the right hemidiaphragm was recorded as an $M$ mode tracing during intermittent positive pressure ventilation and spontaneous breathing. A positive end expiratory pressure of $5 \mathrm{~cm}$ was provided at 